\title{
Preparation and photocatalytic activity of multi-walled carbon nanotubes/Mg-doped $\mathrm{ZnO}$ nanohybrids
}

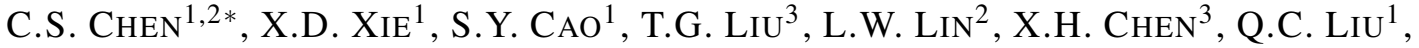 \\ J.C. KUANG ${ }^{1}$, Y. XIAO ${ }^{1}$ \\ ${ }^{1}$ College of Physics and Electronic Science, Changsha University of Science and Technology, Changsha, 410114, \\ People's Republic of China \\ ${ }^{2}$ State Key Laboratory for Powder Metallurgy, Central South University, Changsha, 410083, People's Republic of China \\ ${ }^{3}$ College of Physics and Microelectronics Science, Hunan University, Changsha, 410082, People's Republic of China
}

Multi-walled carbon nanotubes/Mg-doped $\mathrm{ZnO}\left(\mathrm{MWNTs} / \mathrm{Zn}_{1-\mathrm{x}} \mathrm{Mg}_{\mathrm{x}} \mathrm{O}\right.$ ) nanohybrids were prepared by co-precipitation method, and their photocatalytic activity for methyl orange (MO) was studied. Experimental results showed that Mg-doped $\mathrm{ZnO}$ nanoparticles were successfully deposited on the surface of MWNTs under annealing at $450{ }^{\circ} \mathrm{C}$ and $550{ }^{\circ} \mathrm{C}$. The resultant MWNTs $/ \mathrm{Zn}_{0.9} \mathrm{Mg}_{0.1} \mathrm{O}$ nanohybrids had better photocatalytic activity for degradation of methyl orange than pure $\mathrm{ZnO}$ : the rates of MO photodegradation were $100 \%$ and $30 \%$ for $1 \mathrm{~h}$, respectively. The enhancement in the photocatalytic activity was attributed to the excellent electronic properties of MWNTs and Mg-doping.

Keywords: carbon nanotube; $\mathrm{Mg}$-doped $\mathrm{ZnO}$; nanohybrids; photocatalytic activity

(C) Wroclaw University of Technology.

\section{Introduction}

Zinc oxide $(\mathrm{ZnO})$ has attracted great interests due to its high optical activity and stability, wide band gap of $3.37 \mathrm{eV}$, large exciton binding energy $(60 \mathrm{meV})$ at room temperature, low cost and environmental friendliness [1-3]. Such fascinating properties render $\mathrm{ZnO}$ as a promising candidate for the photocatalysis and degradation of various organic pollutants. Unfortunately, there are two major drawbacks for photocatalytic practical application of $\mathrm{ZnO}$. One is that it does not absorb visible light due to its high band gap energy, and the other is that it possesses lower photocatalytic efficiency because of the recombination of photogenerated electron-hole pairs.

In order to utilize solar radiations more effectively, metal and anionic doping were employed previously for improving the photocatalytic activity of $\mathrm{ZnO}$ under sunlight irradiation. Among various dopants, $\mathrm{Mg}^{2+}$ has a ionic radius of $0.57 \AA$,

\footnotetext{
*E-mail: jxccs1934@gmail.com
}

which is very close to the ionic radius of $\mathrm{Zn}^{2+}$ $(0.60 \AA)$, therefore, $\mathrm{Mg}$ ions have a large solubility in $\mathrm{ZnO}$ and ability to replace $\mathrm{Zn}$, but $\mathrm{Mg}$ does not give rise to significant changes in the lattice constants [4]. Mg doping can create localized impurity levels by replacing the $\mathrm{Zn}$ site of $\mathrm{ZnO}$ lattice, or inserting into the crystal lattice of $\mathrm{ZnO}$, resulting in creating localized impurity levels and creating many intermediate energy gaps in $\mathrm{ZnO}$ crystal [5-9]. Therefore, Mg-doping can improve the photocatalytic activity of $\mathrm{ZnO}$ nanostructures significantly [10].

Carbon nanotubes (CNTs) are considered to be an ideal excellent supporting material for catalyst nanoparticles owing to their unique internal structure, high surface area, extremely high mechanical strength, remarkable chemical stability, and outstanding electronic conductivity [11-13]. As a catalyst carrier, CNTs can not only act as photosensitizers for catalysts [14] but also hinder the recombination of electrons and holes [15]. More importantly, CNTs have a large surface area, and can act as a dispersing agent that prevents catalyst 
nanoparticles from agglomerating [16], which results in providing higher active surface area. Thus, CNTs are widely employed to enhance the photocatalytic activity of $\mathrm{ZnO}$ nanoparticles [17-21].

Although there has been a large progress in the synthesis of CNTs/ZnO composite, CNTs often exist in the form of highly tangled ropes, and are poorly dispersible. Furthermore, it is very difficult to control homogeneity and the quality of $\mathrm{ZnO}$ nanoparticles coating the surface of CNTs. In addition, further improvement in the absorption of visible light and increasing optical quantum efficiency are essential prerequisites for boosting photocatalytic activity of $\mathrm{CNTs} / \mathrm{ZnO}$ composite. In this paper, a facile and efficient approach of treating MWNTs has been developed to support $\mathrm{ZnO}$ nanoparticles on MWNTs, and the bandgap of $\mathrm{ZnO}$ nanoparticles has been modulated by $\mathrm{Mg}$ doping. MWNTs were treated by sodium hydroxide and then a mixture of acids. Subsequently, the surface of MWNTs was decorated with Mgdoped $\mathrm{ZnO}$ nanoparticles and the photocatalytic activity of MWNTs/Mg-doped ZnO nanohybrids was studied.

\section{Experimental}

\subsection{Preparation and treatment of MWNTs}

MWNTs used in the experiment were prepared by the chemical catalytic vapor decomposition process (CVD) [22]. The inner diameters, outer diameters and length of the prepared MWNTs were measured to be $10 \mathrm{~nm}, 20 \mathrm{~nm}$ and $1 \mu \mathrm{m}$, respectively. In a typical treatment, 5g as-prepared MWNTs were dispersed in $500 \mathrm{~mL}$ sodium hydroxide $(2 \mathrm{~mol} / \mathrm{L})$ and refluxed at boiling point for $2 \mathrm{~h}$ under stirring. After rinsing with deionized water until the $\mathrm{pH}$ value of solution closed to neutral, the $\mathrm{NaOH}-$ treated MWNTs were dried at $80{ }^{\circ} \mathrm{C}$. In order to remove impurities, these $\mathrm{NaOH}$-treated MWNTs were further oxidized by immersing in a 3:1 mixture of concentrated $\mathrm{H}_{2} \mathrm{SO}_{4}$ and $\mathrm{HNO}_{3}$ and refluxing for $2 \mathrm{~h}$ at boiling point, subsequently dispersing in $500 \mathrm{~mL} \mathrm{HCl}$ solution ( $2 \mathrm{~mol} / \mathrm{L}$ ) and refluxing for another $2 \mathrm{~h}$ at the same temperature. Finally, the
MWNTs were dried at $80{ }^{\circ} \mathrm{C}$ after being filtered and washed with deionized water. The details of treating MWNTs have been described in our previous report [23].

\subsection{Preparation of $M W N T s / Z_{n_{1-x}} M \mathrm{O}$ hybrids}

MWNTs $/ \mathrm{Zn}_{1-\mathrm{x}} \mathrm{Mg}_{\mathrm{x}} \mathrm{O}$ nanohybrids were prepared as follows: Firstly, $0.05 \mathrm{~g}$ of the MWNTs, treated according to previously described procedure, were added into $100 \mathrm{~mL}$ anhydrous ethanol and sonicated for about $15 \mathrm{~min}$, and then $2.2 \mathrm{~g} \mathrm{Zn}\left(\mathrm{CH}_{3} \mathrm{COO}\right)_{2} \cdot 2 \mathrm{H}_{2} \mathrm{O}$ and appropriate $\mathrm{Mg}\left(\mathrm{CH}_{3} \mathrm{COO}\right)_{2} \cdot 2 \mathrm{H}_{2} \mathrm{O}$ (the molar ratios of $\mathrm{Mg}$ to Zn were 5:95, 1:9, 0.2:0.8, and 0.3:0.7, respectively) were added into the MWNTs dispersed in anhydrous ethanol. Subsequently, an appropriate amount of oxalic acid (the molar ratio of metal ion to oxalic acid was 1.1) was dissolved in $100 \mathrm{~mL}$ anhydrous ethanol, and then slowly dropped into the mixture solution of zinc acetate and magnesium acetate, while stirring at $60{ }^{\circ} \mathrm{C}$, and a sol was produced. Thirdly, the sol was maintained at $80{ }^{\circ} \mathrm{C}$ for $48 \mathrm{~h}$ to form the precursor. Finally, the resultant precursor was annealed in nitrogen from room temperature to setting temperature at a rate of $5{ }^{\circ} \mathrm{C} \cdot \mathrm{min}^{-1}$, and then held at the setting temperature for $2 \mathrm{~h}$. The setting temperature was $450{ }^{\circ} \mathrm{C}$, $550{ }^{\circ} \mathrm{C}, 650^{\circ} \mathrm{C}$, and $700^{\circ} \mathrm{C}$, respectively. For comparison, the $\mathrm{ZnO}$ nanoparticles and MWNTs/ZnO nanohybrids annealed at $650{ }^{\circ} \mathrm{C}$ were prepared under the same conditions.

\subsection{Characterization}

Infrared spectroscopy was performed using a $300 \mathrm{E}$ Jasco spectrophotometer at room temperature. X-ray diffraction (XRD) measurements were performed using Philips PW 1710 diffractometer with $\mathrm{CuK} \alpha_{1}$ radiation. The nature of chemical state of MWNTs nanohybrids was analysed using X-ray photoelectron spectroscopy (XPS) with a Kratos AXIS-165 spectrometer. Scanning electron microscopy (SEM) observations and the energy dispersive X-ray spectroscopy (EDS) were carried out with an S-4800 field emission scanning electron microscope. Transmission electron 
microscopy (TEM) analyses were conducted on a JEM-3010 transmission electron microscope. Fluorescence spectra measurements were performed for anhydrous ethanol on a Hitachi F4500 fluorescence spectrophotometer at room temperature.

Methyl orange (MO) was used as a model dye to evaluate the photocatalytic activity of MWNTs/Mg-doped ZnO hybrids. In a typical experiment, $50 \mathrm{mg}$ catalyst was dispersed in $200 \mathrm{~mL}$ of $20 \mathrm{~g} / \mathrm{L} \mathrm{MO}$ aqueous solution. The above reaction mixture was magnetically stirred for $30 \mathrm{~min}$ in dark, and then the photoreactions were conducted at room temperature under a high pressure Osram Ultra-Vitalux lamp (100 W, wave length $365 \mathrm{~nm}$ ) positioned horizontally above the liquid surface (the lamp was placed at about $40 \mathrm{~cm}$ above the solution surface). The methyl orange aqueous solution was magnetically stirred throughout the photocatalytic experiment to ensure the full suspension of particles. The experiments were conducted for 60 min with $3 \mathrm{~mL}$ sample aliquots extracted every $15 \mathrm{~min}$ and subsequently centrifuged at $4000 \mathrm{rpm}$ for $10 \mathrm{~min}$. The decomposition of methyl orange was monitored by measuring the absorbance of the supernatant at $464 \mathrm{~nm}$ using TU-2550 spectrophotometer. The degradation ratio was calculated with $\left(\mathrm{C} / \mathrm{C}_{0}\right)$, where $\mathrm{C}_{0}$ is the initial concentration and $\mathrm{C}$ is the concentration of $\mathrm{MO}$ in solution at different time.

\section{Results and discussion}

\subsection{Infrared spectrum analysis}

Fig. 1 shows the infrared spectra of different MWNTs. It can be seen that no peaks are observed in the spectrum of pristine MWNTs (curve a in Fig. 1). However, when the MWNTs were treated, many groups were introduced onto their surfaces. There were carbonyl groups revealed at about $1705 \mathrm{~cm}^{-1}$, oxygen-hydrogen bonds and $\mathrm{C}=\mathrm{C}$ bonds revealed at about $3427 \mathrm{~cm}^{-1}$ and $1568 \mathrm{~cm}^{-1}$, respectively, as shown in curve $\mathrm{b}$ and curve $\mathrm{c}$ of Fig. 1. It is worth noting that $\mathrm{NaOH}$ treatment could enhance the intensity of oxygenhydrogen bonds significantly, which indicates that the surface activity of MWNTs has been further improved.

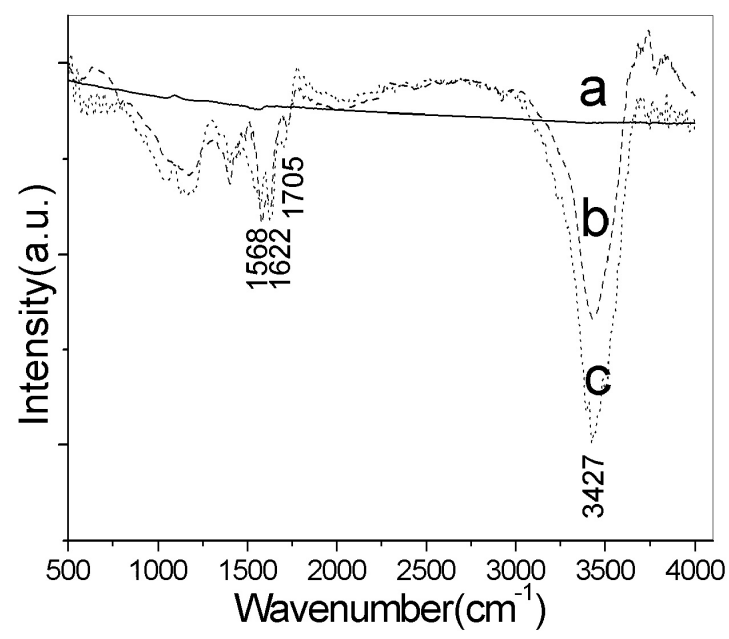

Fig. 1. Infrared spectrum of different MWNTs: (a) asprepared, (b) treated by mixture acid, and (c) treated by $\mathrm{NaOH}$ and mixture acid.

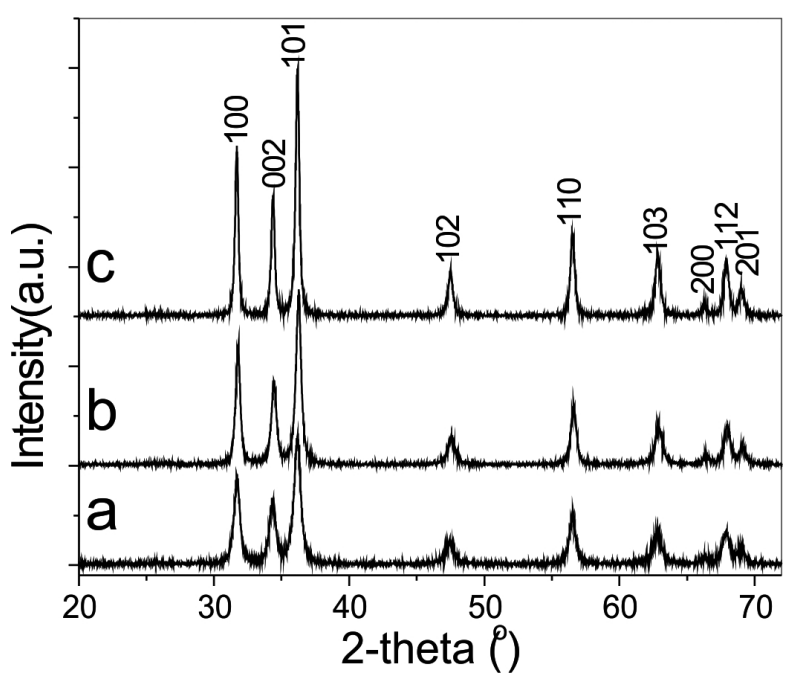

Fig. 2. XRD patterns of the MWNTs $/ Z_{0.9} M_{0.1} \mathrm{O}$ nanohybrid annealed at different temperatures: (a) $450{ }^{\circ} \mathrm{C}$, (b) $550{ }^{\circ} \mathrm{C}$, (c) $650{ }^{\circ} \mathrm{C}$.

\subsection{XRD analysis}

Fig. 2 displays the XRD patterns of MWNTs $/ \mathrm{ZnO}_{0.9} \mathrm{Mg}_{0.1} \mathrm{O}$ nanohybrid subjected to heat treatment at different temperatures. It has been found that all samples exhibit the diffraction peaks of $\mathrm{ZnO}$ corresponding to (100), (002), (101), (102), (110), (103), (200), (112) and (201) planes, respectively. All diffraction peaks of the samples are in good agreement with those of the 
hexagonal wurtzite structure of $\mathrm{ZnO}$ (JCPDS Card No. 36-1451). Comparison of the three curves shows that the diffraction peaks become sharper and narrower with increasing temperature of heat treatment, which indicates that the crystallite size increases along with the rise of temperature of heat treatment. Furthermore, no traces of magnesium metal, oxides, or any binary zinc magnesium phases are observed in the XRD pattern. This result illustrates that doping with $\mathrm{Mg}$ may replace the $\mathrm{Zn}$ site of $\mathrm{ZnO}$ lattice, or insert into the crystal lattice of $\mathrm{ZnO}$.

\subsection{SEM studies}

SEM images of MWNTs/ $\mathrm{Zn}_{0.9} \mathrm{Mg}_{0.1} \mathrm{O}$ nanohybrids annealed at different temperatures are shown in Fig. 3. As shown in Fig. 3a, it can be found that MWNTs $/ \mathrm{Zn}_{0.9} \mathrm{Mg}_{0.1} \mathrm{O}$ nanohybrids annealed at $450{ }^{\circ} \mathrm{C}$ are composed of nanowires, and the nanoparticle size is about $10 \mathrm{~nm}$. However, when the temperature of heat treatment was increased to $550{ }^{\circ} \mathrm{C}$, the $\mathrm{MWNTs} / \mathrm{Zn}_{0.9} \mathrm{Mg}_{0.1} \mathrm{O}$ nanohybrids were still composed of nanowires but the nanoparticle size changed into about $20 \mathrm{~nm}$ (Fig. 3b). Further increasing of the treatment temperature up to $650{ }^{\circ} \mathrm{C}$, resulted in the MWNTs/ $/ \mathrm{Zn}_{0.9} \mathrm{Mg}_{0.1} \mathrm{O}$ nanohybrids composed of MWNTs and nanoparticles with the size of about $60 \mathrm{~nm}$ (Fig. 3c). Fig. $3 \mathrm{~d}$ displays the SEM images of $\mathrm{Zn}_{0.9} \mathrm{Mg}_{0.1} \mathrm{O}$ nanohybrids annealed at $650{ }^{\circ} \mathrm{C}$. It is clear that the nanoparticles reunited to large aggregates. This result implies that MWNTs can improve the dispersion of nanoparticles.

In order to analyse the elements present in the nanoparticles on the surface of MWNTs, EDS was carried out, and the ratio of each element is shown in Table 1. It reveals the presence of $\mathrm{Zn}, \mathrm{O}, \mathrm{Mg}$, and $\mathrm{C}$, which confirms that the nanoparticles on the surface of MWNTs are Mg-doped $\mathrm{ZnO}$ nanoparticles. From Table 1, we can conclude that the ratio of $\mathrm{Zn}$ to $\mathrm{Mg}$ increased as the annealed temperature increased, however, the ratio of $\mathrm{O}$ to metal element decreased. When the annealing temperature was $450{ }^{\circ} \mathrm{C}$, the ratios of $\mathrm{Zn}$ to $\mathrm{Mg}$ and $\mathrm{O}$ to metal were about 7.12 and 1.44 , respectively. After increasing the annealing temperature to $650{ }^{\circ} \mathrm{C}$,

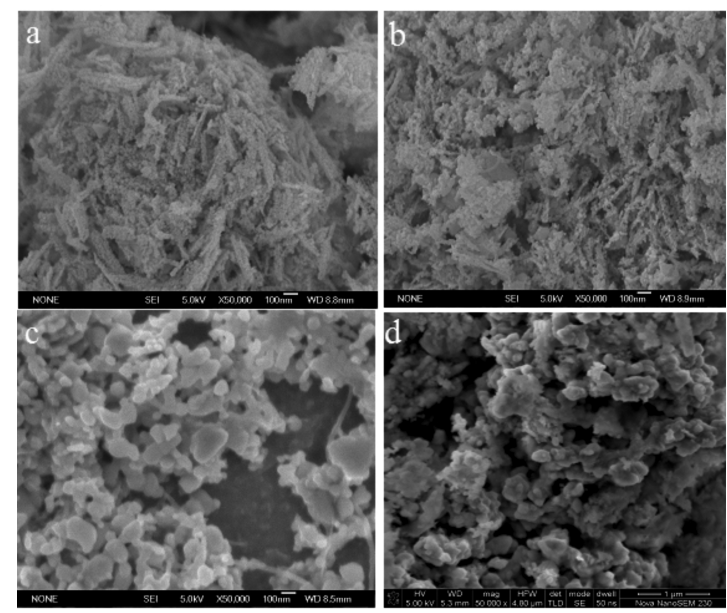

Fig. 3. SEM images of MWNTs/Zn $\mathrm{Zn}_{0.9} \mathrm{Mg}_{0.1} \mathrm{O}$ nanohybrids annealed at $450{ }^{\circ} \mathrm{C}$ (a), $550{ }^{\circ} \mathrm{C}$ (b), and $650{ }^{\circ} \mathrm{C}$ (c); SEM images of $\mathrm{Zn}_{0.9} \mathrm{Mg}_{0.1} \mathrm{O}$ nanohybrids annealed at $650^{\circ} \mathrm{C}(\mathrm{d})$.

their ratios changed to 9.2 and 0.88 , respectively. These results show that the annealing temperature affects the oxygen vacancies and zinc vacancies of $\mathrm{ZnO}$ crystal.

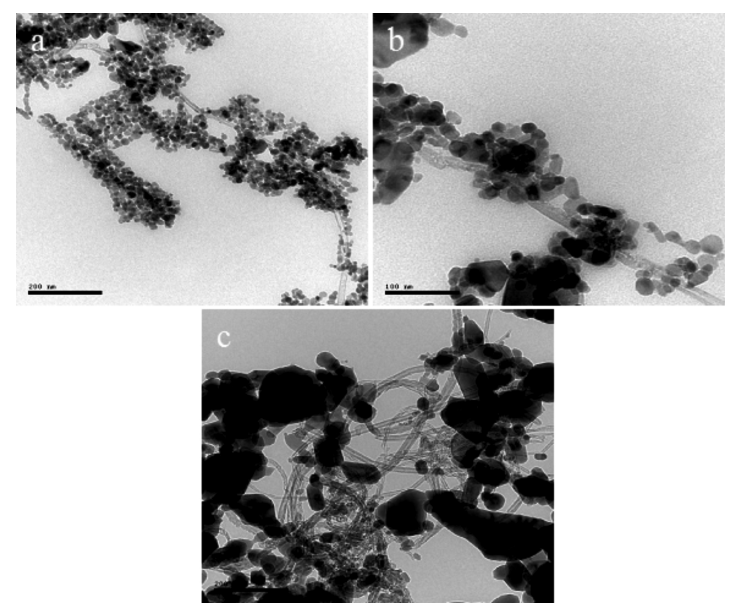

Fig. 4. TEM images of MWNTs/ $/ \mathrm{Zn}_{0.9} \mathrm{Mg}_{0.1} \mathrm{O}$ nanohybrids annealed at different temperatures: (a) $450{ }^{\circ} \mathrm{C}$, (b) $550{ }^{\circ} \mathrm{C}$, and (c) $650{ }^{\circ} \mathrm{C}$.

\subsection{TEM studies}

TEM studies further confirmed the successful attachment of $\mathrm{Mg}$-doped $\mathrm{ZnO}$ nanoparticles to the walls of MWNTs, as shown in Fig. 4. Fig. 4a shows the TEM image of MWNTs/ $Z_{0.9} \mathrm{Mg}_{0.1} \mathrm{O}$ 
Table 1. the EDS of different samples.

\begin{tabular}{|c|c|c|c|c|}
\hline Element & $\mathrm{C}($ at. \%) & $\mathrm{O}($ at. $\%)$ & $\mathrm{Zn}($ at. \%) & $\mathrm{Mg}$ (at.\%) \\
\hline MWNTs $/ \mathrm{Zn}_{0.9} \mathrm{Mg}_{0.1} \mathrm{O}$ nanohybrids annealed at $450^{\circ} \mathrm{C}$ & 16.91 & 49.06 & 29.84 & 4.19 \\
\hline MWNTs $/ \mathrm{Zn}_{0.9} \mathrm{Mg}_{0.1} \mathrm{O}$ nanohybrids annealed at $550{ }^{\circ} \mathrm{C}$ & 13.43 & 47.68 & 34.47 & 4.42 \\
\hline MWNTs $/ \mathrm{Zn}_{0.9} \mathrm{Mg}_{0.1} \mathrm{O}$ nanohybrids annealed at $650{ }^{\circ} \mathrm{C}$ & 10.82 & 41.88 & 42.68 & 4.63 \\
\hline
\end{tabular}

nanohybrids annealed at $450{ }^{\circ} \mathrm{C}$. It is evident that the surface of the MWNTs is decorated by a large number of nanoparticles, and the size distribution of the $\mathrm{ZnO}$ nanoparticles is narrow, with an average particle size of about $10 \mathrm{~nm}$. Fig. $4 \mathrm{~b}$ reveals the TEM image of MWNTs $/ \mathrm{Zn}_{0.9} \mathrm{Mg}_{0.1} \mathrm{O}$ nanohybrids annealed at $550{ }^{\circ} \mathrm{C}$. It can be observed that the MWNTs are continuously coated by nanoparticles with the size of about $20 \mathrm{~nm}$. When the temperature of heat treatment reached $650{ }^{\circ} \mathrm{C}$, not only the particle size of nanoparticles further increased, but also the discontinuity in the coating became apparent, as shown in Fig. 4c. These results illustrate that the size of nanoparticles on the surface of MWNTs increased with increasing the annealing temperature.

\subsection{XPS analysis}

The composition and chemical states of the MWNTs $/ \mathrm{Zn}_{0.9} \mathrm{Mg}_{0.1} \mathrm{O}$ nanohybrid were analyzed using XPS spectra. Fig. 5 displays the $\mathrm{O} 1 \mathrm{~s}$, Zn $2 \mathrm{p}$, and $\mathrm{Mg} 1 \mathrm{~s}$ XPS spectra of MWNTs/ZnO and MWNTs $/ \mathrm{Zn}_{0.9} \mathrm{Mg}_{0.1} \mathrm{O}$ nanohybrid annealed at $650{ }^{\circ} \mathrm{C}$. It is demonstrated in Fig. 5a that the $\mathrm{O}$ 1 s core-level spectrum of nanohybrid shows three $\mathrm{O} 1 \mathrm{~s}$ peaks and a $\mathrm{O} 1 \mathrm{~s}$ peak band. The $\mathrm{O} 1 \mathrm{~s}$ peak positioned at the lower binding energy of $529.8 \mathrm{eV}$ has been assigned to $\mathrm{O}^{2-}$ ions in the $\mathrm{Zn}-\mathrm{O}$ binding of wurtzite structure of $\mathrm{ZnO}$. The two peaks located at 530.2 and $530.8 \mathrm{eV}$ have been ascribed to the added contribution from $\mathrm{Zn}-\mathrm{O}-\mathrm{Mg}$ and $\mathrm{Mg}-\mathrm{O}$ bonds, respectively. The band located at $532.0 \mathrm{eV}$ is attributed to the $\mathrm{Zn}-\mathrm{OH}$ bonding, which is in agreement with the previous report of Mg-doped $\mathrm{ZnO}$ thin film [24]. From Fig. 5b, it can be seen that the $\mathrm{Zn} 2 \mathrm{p}$ core-level of MWNTs/ZnO nanohybrid has two fitting peaks located at about 1044.30 and $1021.30 \mathrm{eV}$ attributed to $\mathrm{Zn} 2 \mathrm{p}_{1 / 2}$ and
$\mathrm{Zn} 2 \mathrm{p}_{3 / 2}$, respectively. Similarly, the $\mathrm{Zn} 2 \mathrm{p}$ corelevel of MWNTs/ $\mathrm{Zn}_{0.9} \mathrm{Mg}_{0.1} \mathrm{O}$ nanohybrids have two fitting peaks shifted towards the higher binding energy. Those two fitting peaks are located at about 1044.70 and $1021.70 \mathrm{eV}$, respectively. Moreover, it can be seen that the binding energy difference between the $\mathrm{Zn} 2 \mathrm{p}_{1 / 2}$ and $\mathrm{Zn} 2 \mathrm{p}_{3 / 2}$ is $23 \mathrm{eV}$ for all MWNTs nanohybrids. These results indicate that the chemical valence of $\mathrm{Zn}$ at the surface of MWNTs nanohybrids is +2 oxidation state [25]. The Mg 1s peak is shown in Fig. 5c. Mg1s peak at $1303.98 \mathrm{eV}$ belongs to the $\mathrm{Mg}-\mathrm{O}$ bonding in $\mathrm{ZnO}$ [26]. XPS measurements combined with XRD results demonstrated that the $\mathrm{Mg}$ successfully replaced the $\mathrm{Zn}$ site of $\mathrm{ZnO}$ lattice.

\subsection{Decoration mechanism}

We presumed that the MWNTs-supported Mgdoped $\mathrm{ZnO}$ nanoparticles were attributed to enhance the surface activity of MWNTs by the treatment with $\mathrm{NaOH}$ solution and mixture acid. After MWNTs were treated by $\mathrm{NaOH}$ and mixture acid, more defects were produced on the walls of MWNTs, which was also favorable for the deposition of nanoparticles on the surface of MWNTs. Fig. 6 displays the HRTEM images of different MWNTs. It can be seen that there is an amorphous layer on the outer layer of pristine MWNTs, as shown in Fig. 6a. After treating MWNTs with $\mathrm{NaOH}$ and mixture acid, not only the amorphous layer was eliminated completely, but also some defects on the outer wall of MWNTs have revealed (Fig. 6b). This result illustrates that the carbon atoms of MWNTs walls were etched by $\mathrm{NaOH}$ solution and mixture acid.

In addition, the decorating nanoparticles on the surface of MWNTs can be attributed to the oxygen functional groups, such as carboxyl 

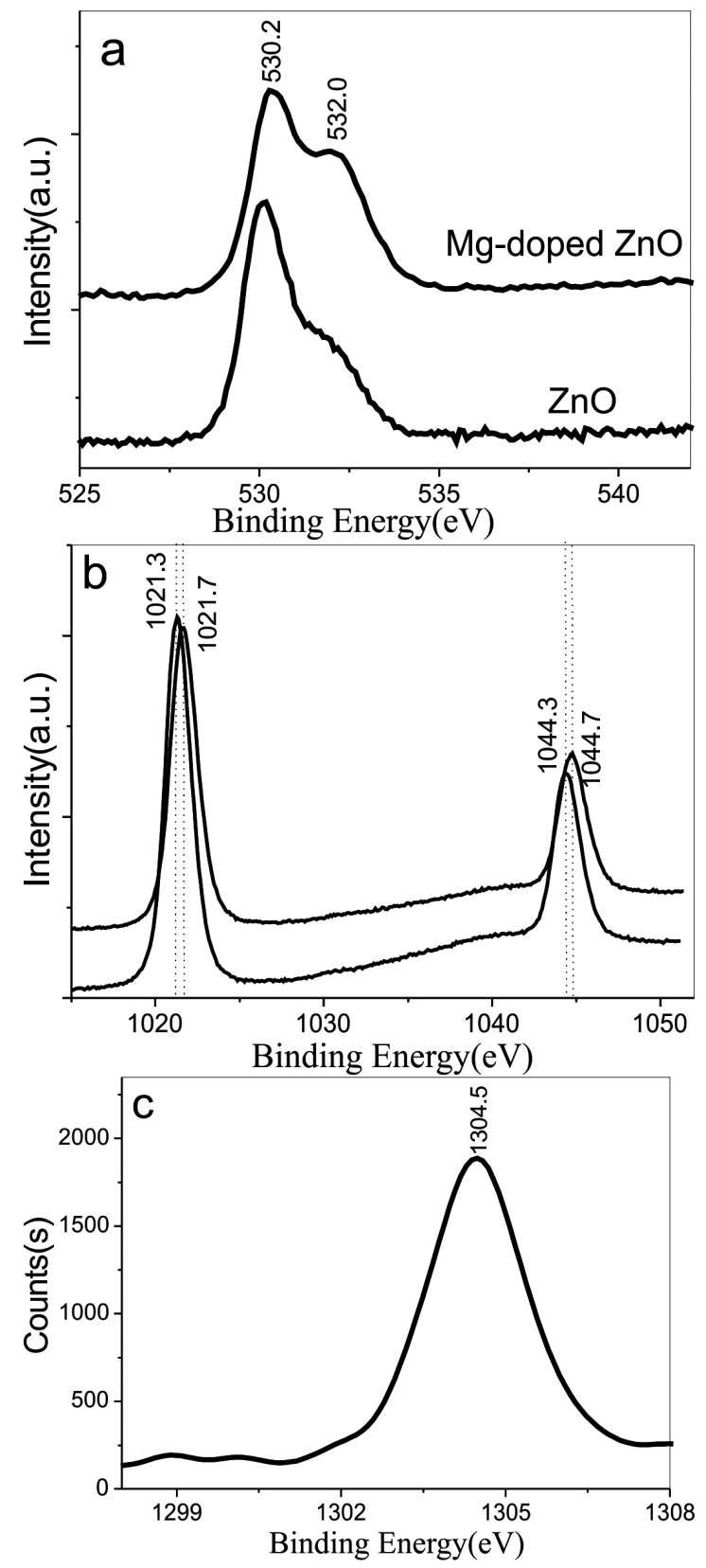

Fig. 5. XPS spectrum of MWNTs/ZnO nanohybrid and MWNTs $/ \mathrm{Zn}_{0.9} \mathrm{Mg}_{0.1} \mathrm{O}$ nanohybrid annealed at $650{ }^{\circ} \mathrm{C}$ : (a) O 1s, (b) Zn 2p, and (c) Mg 1s.

groups and oxygen-hydrogen groups, facilitating the interaction between MWNTs and oxalate precursor. These oxygen functional groups on the walls of MWNTs can improve the chemical activity and dispersion of MWNTs. Furthermore, these carboxyl groups can form carboxyl group with negative charge in solution, and easily attract
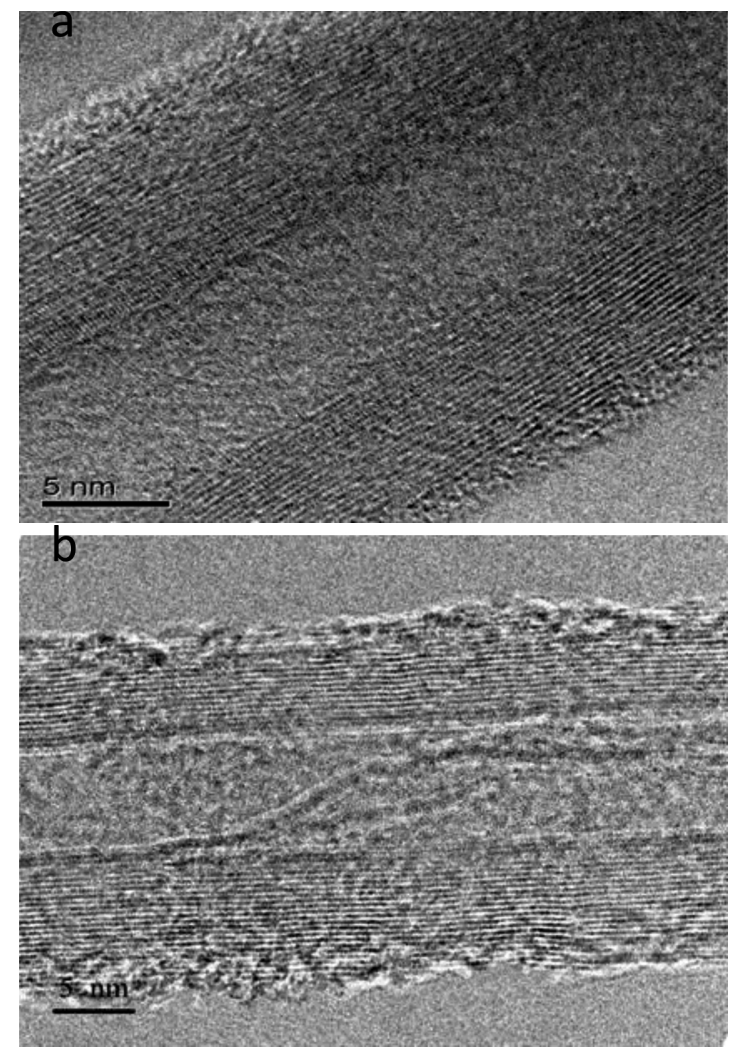

Fig. 6. TEM images of different MWNTs: (a) asprepared and (b) treated by $\mathrm{NaOH}$.

positively charged metal ions through electrostatic interactions. When the $\mathrm{H}_{2} \mathrm{C}_{2} \mathrm{O}_{4}$ and $\mathrm{C}_{2} \mathrm{H}_{5} \mathrm{OH}$ were added, the $\mathrm{Zn}^{2+}$ and $\mathrm{Mg}^{2+}$ easily formed $\mathrm{ZnC}_{2} \mathrm{O}_{4}$ and $\mathrm{MgC}_{2} \mathrm{O}_{4}$, which underwent the combination reaction as described in equation 1 . The $\mathrm{CH}_{3} \mathrm{COOH}$ can react with $\mathrm{C}_{2} \mathrm{H}_{5} \mathrm{OH}$ by esterification (equation 2), accelerated towards the right (equation 1) and help in the formation of $\mathrm{ZnC}_{2} \mathrm{O}_{4}$ and $\mathrm{MgC}_{2} \mathrm{O}_{4}$. The reaction of combination (equation 1) and esterification (equation 2) happened almost at the same time. Ultimately, all the $\mathrm{Zn}^{2+}$ and $\mathrm{Mg}^{2+}$ were turned into oxalate precursor. Every metal ion was bonded by $\mathrm{C}_{2} \mathrm{O}_{4}^{2-}$ ions to form a planar molecule in the complexes. There were two coordinated $\mathrm{H}_{2} \mathrm{O}$ molecules at each side of the molecular plane and two molecular planes were connected by the $\mathrm{H}_{2} \mathrm{O}$ molecule (shown in Fig. 7). Hence, MWNTs can uniformly support oxalate precursor by hydrogen bond in ethanol solution. Finally, when the MWNTs/oxalate 
precursor was annealed at low temperature, the oxalate precursor released $\mathrm{CO}$ and $\mathrm{CO}_{2}$ gas, simultaneosly producing $\mathrm{ZnO}$ and $\mathrm{MgO}$, resulting in formation of $\mathrm{Mg}$-doped $\mathrm{ZnO}$ nanoparticles accumulating on the surface of MWNTs. The chemical reaction was displayed in equation 3 . When the heating time was prolonged, the small oxide nanoparticles nucleated on MWNTs and grew into large oxide crystallites. Therefore, the MWNTs could be decorated by nanoparticles uniformly. However, when the MWNTs/oxalate precursor was annealed at high temperature, the particle size on MWNTs further increased, resulting in MWNTs protruding from the nanoparticles.

$$
\begin{aligned}
& \mathrm{Zn}\left(\mathrm{CH}_{3} \mathrm{COO}\right)_{2} \cdot 2 \mathrm{H}_{2} \mathrm{O}+\mathrm{H}_{2} \mathrm{C}_{2} \mathrm{O}_{4} \cdot 2 \mathrm{H}_{2} \mathrm{O} \rightarrow \\
& \rightarrow \mathrm{ZnC}_{2} \mathrm{O}_{4} \cdot 2 \mathrm{H}_{2} \mathrm{O}+2 \mathrm{CH}_{3} \mathrm{COOH}+2 \mathrm{H}_{2} \mathrm{O} \\
& \mathrm{Mg}\left(\mathrm{CH}_{3} \mathrm{COO}\right)_{2} \cdot 2 \mathrm{H}_{2} \mathrm{O}+\mathrm{H}_{2} \mathrm{C}_{2} \mathrm{O}_{4} \cdot 2 \mathrm{H}_{2} \mathrm{O} \rightarrow \\
& \rightarrow \mathrm{MgC}_{2} \mathrm{O}_{4} \cdot 2 \mathrm{H}_{2} \mathrm{O}+2 \mathrm{CH}_{3} \mathrm{COOH}+2 \mathrm{H}_{2} \mathrm{O}
\end{aligned}
$$

$$
\mathrm{CH}_{3} \mathrm{COOH}+\mathrm{C}_{2} \mathrm{H}_{5} \mathrm{OH} \rightarrow \mathrm{CH}_{3} \mathrm{COOC}_{2} \mathrm{H}_{5}+\mathrm{H}_{2} \mathrm{O}
$$

$$
\begin{aligned}
& \mathrm{ZnC}_{2} \mathrm{O}_{4} \rightarrow \mathrm{ZnO}+\mathrm{CO}_{2}+\mathrm{CO} \\
& \mathrm{MgC}_{2} \mathrm{O}_{4} \rightarrow \mathrm{MgO}+\mathrm{CO}_{2}+\mathrm{CO}
\end{aligned}
$$

\subsection{Photocatalytic studies}

Methyl orange (MO) is a common organic dye with orange color, which is widely used to evaluate the photocatalytic activity of photocatalysts [27]. Fig. 8 depicts the photocatalytic photodegradation efficiency of different samples for MO. The photocatalysts loading content is $0.25 \mathrm{~g} / \mathrm{L}$. It is found that the blank test (without any sample) has shown only a small amount of MO degradation. The photoactivity of the MWNTs/ $\mathrm{Zn}_{0.9} \mathrm{Mg}_{0.1} \mathrm{O}$ samples has been enhanced with increasing annealing temperature from $450{ }^{\circ} \mathrm{C}$ to $650{ }^{\circ} \mathrm{C}$. When the annealing temperature increased beyond $650{ }^{\circ} \mathrm{C}$, the photocatalytic performance decreased. These results indicate that the optimum annealing temperature is $650{ }^{\circ} \mathrm{C}$. This is because the nanoparticles on MWNTs became larger under high annealing temperature, and MWNTs were devoid of nanoparticles, resulting in weakening the interaction of MWNTs and nanoparticles.

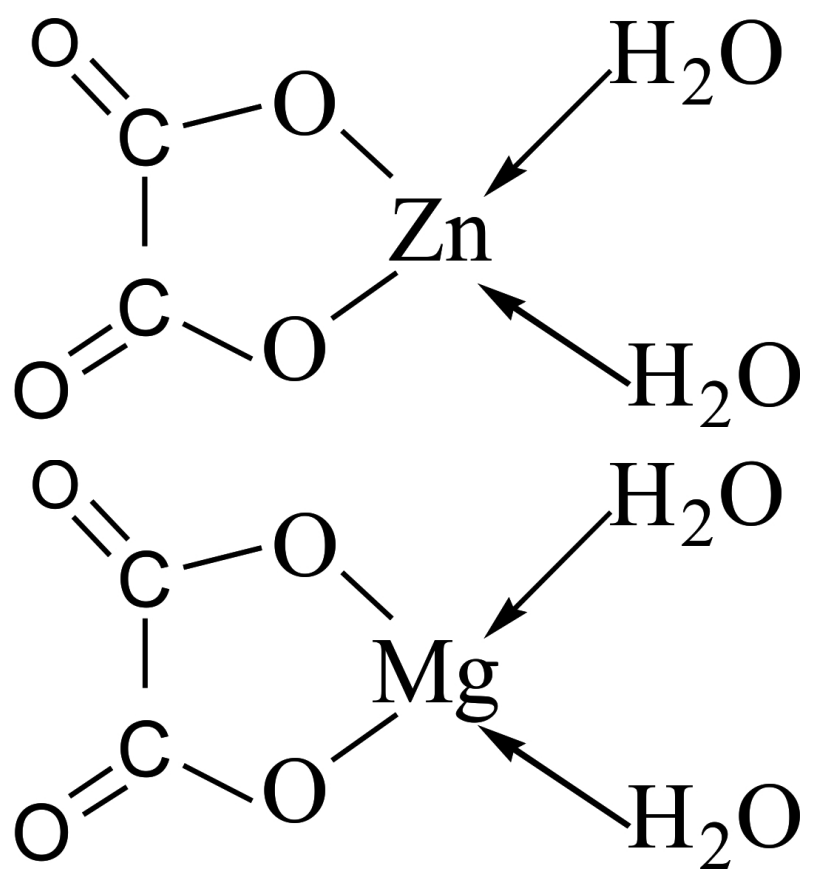

Fig. 7. The structures of $\mathrm{ZnC}_{2} \mathrm{O}_{4} \cdot 2 \mathrm{H}_{2} \mathrm{O}$ and $\mathrm{MgC}_{2} \mathrm{O}_{4} \cdot 2 \mathrm{H}_{2} \mathrm{O}$ precursors.

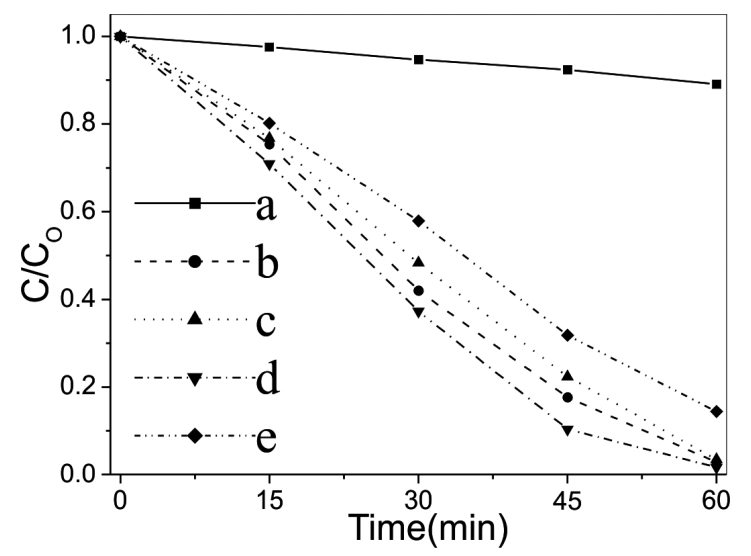

Fig. 8. Photocatalytic performance of MWNTs/ $\mathrm{Zn}_{0.9} \mathrm{Mg}_{0.1} \mathrm{O}$ nanohybrids at different annealing temperatures: (a) blank, (b) $450{ }^{\circ} \mathrm{C}$, (c) $550{ }^{\circ} \mathrm{C}$, (d) $650{ }^{\circ} \mathrm{C}$, (e) $700{ }^{\circ} \mathrm{C}$.

To study the effect of Mg-doping content on the photocatalytic activity of MWNTs/ $\mathrm{Zn}_{1-\mathrm{x}} \mathrm{Mg}_{\mathrm{x}} \mathrm{O}$ nanohybrids, we tested the photocatalytic activity of MWNTs $/ \mathrm{Zn}_{1-\mathrm{x}} \mathrm{Mg}_{\mathrm{x}} \mathrm{O}$ nanohybrids annealed at $650{ }^{\circ} \mathrm{C}$, and the result is shown in Fig. 9. Obviously, the amount of MO degraded by the pure $\mathrm{ZnO}$ sample was about $34 \%$ after $60 \mathrm{~min}$, and the 


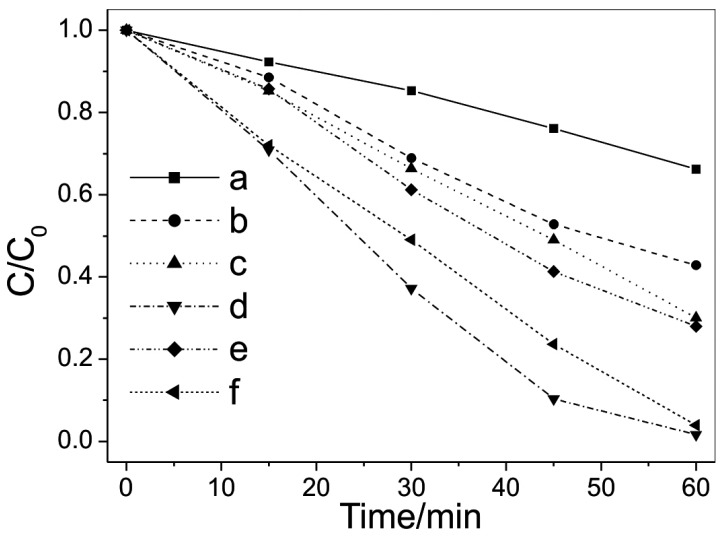

Fig. 9. Photocatalytic performance of MWNTs/ $\mathrm{Zn}_{1-\mathrm{x}} \mathrm{Mg}_{\mathrm{x}} \mathrm{O}$ nanohybrids annealed at $650{ }^{\circ} \mathrm{C}$ :

(a) $\mathrm{ZnO}$, (b) $\mathrm{MWNTs} / \mathrm{ZnO}$ nanohybrids,

(c) MWNTs/ $\mathrm{Zn}_{0.95} \mathrm{Mg}_{0.05} \mathrm{O}$ nanohybrids,

(d) $\mathrm{MWNTs} / \mathrm{Zn}_{0.9} \mathrm{Mg}_{0.1} \mathrm{O}$ nanohybrids, (e)

MWNTs/ $\mathrm{Zn}_{0.8} \mathrm{Mg}_{0.2} \mathrm{O}$ nanohybrids, (f)

MWNTs/ $\mathrm{Zn}_{0.7} \mathrm{Mg}_{0.3} \mathrm{O}$ nanohybrids.

MWNTs/ZnO hybrid sample exhibited higher photocatalytic degradation efficiency than pure $\mathrm{ZnO}$ sample, which came up to about $58 \%$. It is worth to note that the photocatalytic degradation efficiency of all MWNTs/ $/ \mathrm{n}_{1-\mathrm{x}} \mathrm{Mg}_{\mathrm{x}} \mathrm{O}$ hybrids was higher than that of the MWNTs/ZnO nanohybrids sample, in which the amount of degraded MO was about $100 \%$ within $60 \mathrm{~min}$, implying that the photocatalytic ability of MWNTs/ZnO hybrids for MO was improved by $\mathrm{Mg}$-doping. Also, the photocatalytic activity of the samples was enhanced with increasing $\mathrm{Mg}$ concentration from 0 to 0.1 . As the $\mathrm{Mg}$ content increased beyond 0.1 , the photocatalytic activity decreased. These results indicated that there was an optimum ratio between $\mathrm{Mg}$ element and $\mathrm{Zn}$ element for improving the photocatalytic activity, and the optimum mass ratio of $\mathrm{Mg}$ to $\mathrm{Zn}$ was 1:9.

\subsection{Fluorescence analysis}

Fig. 10 shows the room-temperature fluorescence spectra of different samples, obtained at the wavelength of excitation of $320 \mathrm{~nm}$. There is a UV peak at about $354 \mathrm{~nm}$ on the spectrum of MWNTs (curve a in Fig. 10a), which comes from the trapping of excitation energy at defect sites of MWNTs and the increasing of energy gap between the lowest empty orbit and the highest occupied orbital

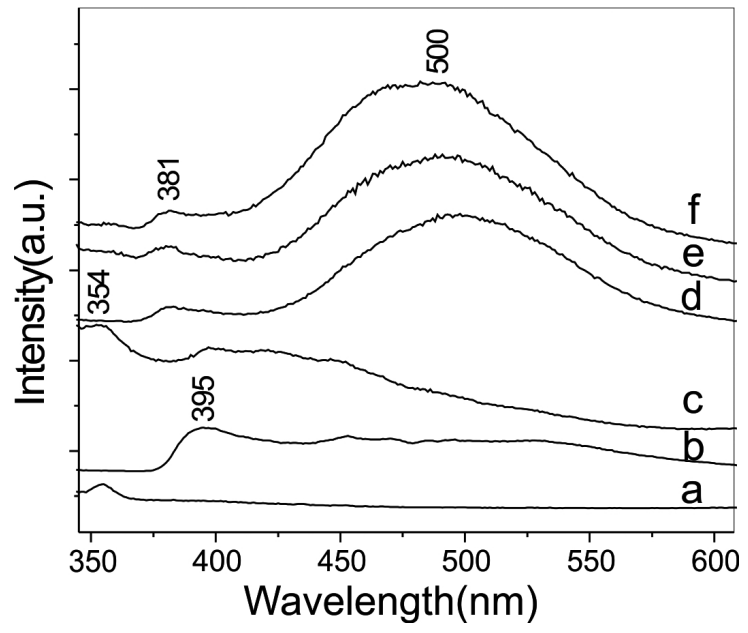

Fig. 10. Fluorescence spectra of different samples: (a) MWNTs, (b) pure ZnO, (c) MWNTs/ $\mathrm{ZnO}$ hybrid annealed at $450{ }^{\circ} \mathrm{C}$, (d) MWNTs $/ \mathrm{Zn}_{0.9} \mathrm{Mg}_{0.1} \mathrm{O}$ hybrid annealed at $450{ }^{\circ} \mathrm{C}$, (e) $\mathrm{MWNTs} / \mathrm{Zn}_{0.9} \mathrm{Mg}_{0.1} \mathrm{O}$ hybrid annealed at $550{ }^{\circ} \mathrm{C}$, (f) $\mathrm{MWNTs} / \mathrm{Zn}_{0.9} \mathrm{Mg}_{0.1} \mathrm{O}$ hybrid annealed at $650{ }^{\circ} \mathrm{C}$.

of the modified MWNTs [28]. Then, the fluorescence spectrum of $\mathrm{ZnO}$ nanoparticle (curve $\mathrm{b}$ in Fig. 10) shows the UV emission peak at $395 \mathrm{~nm}$, which originates from the exciton recombination corresponding to the near-band edge (NBE) exciton emission of the wide band gap $\mathrm{ZnO}$, namely, the free excitons recombination through excitonexciton collision process. In the fluorescence spectrum of MWNTs/ZnO hybrid annealed at $450{ }^{\circ} \mathrm{C}$, there is a UV peak at about $354 \mathrm{~nm}$ besides the intrinsic peak of $\mathrm{ZnO}$ at $395 \mathrm{~nm}$, as shown in curve c in Fig. 10. However, the fluorescence spectra of all MWNTs $/ Z_{0.9} \mathrm{Mg}_{0.1} \mathrm{O}$ hybrids (shown in curves $\mathrm{d}$, e and $\mathrm{f}$ in Fig. 10) include an UV emission peak at about $381 \mathrm{~nm}$ and a green emission band center at about $500 \mathrm{~nm}$, which can be attributed to the singly ionized oxygen vacancy in the $\mathrm{ZnO}$ nanostructures [29].

The blue-shift of ultraviolet emission peak is attributed to $\mathrm{Mg}$ replacing the zinc site of $\mathrm{ZnO}$ lattice, which results in extending the band gap of $\mathrm{ZnO}$ towards the deep UV region in the $\mathrm{ZnO}$ [30]. Moreover, the blue-shift of ultraviolet emission peak may originate from Moss-Burstein effect, which describes the upward movement of Fermi 
level with $\mathrm{Mg}$ doping [31]. Because the sizes of the samples are much larger than the exciton Bohr radius of $1.8 \mathrm{~nm}$, we think that the blue-shift of green emission peak does not originate from quantum confinement effects, but rather is attributed to $\mathrm{Mg}$ replacing the zinc site of $\mathrm{ZnO}$ lattice. When magnesium replaces the zinc site of $\mathrm{ZnO}$ lattice, oxygen vacancies and electron concentration increase. Generally, as the Fermi level of intrinsic $\mathrm{ZnO}$ is inside the conduction band, many electrons generated by $\mathrm{Mg}$ dopant locate at a higher Fermi level. Therefore, the radiative recombination of excitons causes a buleshift [32]. Furthermore, the substitution of $\mathrm{Zn}$ by $\mathrm{Mg}$ makes the polarization of its neighboring $\mathrm{O}^{2-}$ ion decrease, causing the defect band to move towards the ultraviolet [33]. Meanwhile, the Mg-doping can shift the conduction-band and valence-band levels to the same degree in relation to the $\mathrm{V}_{\mathrm{O}}$ level [34].

In addition, with increasing doping of $\mathrm{Mg}$ in $\mathrm{ZnO}$, we found that the ultraviolet emission peak of $\mathrm{ZnO}$ shifted from $395 \mathrm{~nm}$ to $381 \mathrm{~nm}$, and the intensity of the green emission peak was greater than that of ultraviolet emission peak. Furthermore, the green emission peak shifted to blue region with increasing the $\mathrm{Mg}$-doping content in $\mathrm{ZnO}$. The blueshift of ultraviolet emission peak is attributed to $\mathrm{Mg}$ replacing the site of $\mathrm{ZnO}$ lattice, resulting in extending the band gap of $\mathrm{ZnO}$ towards the deep UV region of the $\mathrm{ZnO}$. The enhancement of green emission peak can be explained that when magnesium replaces the zinc site of $\mathrm{ZnO}$ lattice or inserts into the $\mathrm{Zn}$ interstitial, the lattice of $\mathrm{ZnO}$ is distorted and forms oxygen vacancies and zinc vacancies, resulting in improving the intensity of green emission peak significantly [35]. These results indicate that some $\mathrm{Mg}$ cations in the hybrids are incorporated in the $\mathrm{Zn}$ cation sites, and others $\mathrm{Mg}$ cations are inserted into the $\mathrm{Zn}$ interstitial.

\subsection{Photocatalytic mechanism}

As we discussed above, it has been concluded that the enhancement in photocatalytic activity is attributed to the outstanding electrical property of MWNTs and the defects in the $\mathrm{ZnO}$ crystals caused by Mg-doping. When magnesium replaces the zinc site of $\mathrm{ZnO}$ lattice or inserts into the $\mathrm{Zn}$ interstitial, the lattice of $\mathrm{ZnO}$ is distorted and forms oxygen vacancies and zinc vacancies, resulting in creating intermediate energy gap in $\mathrm{ZnO}$ crystal. The intermediate energy gap can promote the absorption of photons and create electron-hole pairs. Under UVlight irradiation, the electrons $\left(\mathrm{e}^{-}\right)$in the valence band (VB) of $\mathrm{ZnO}$ are excited to the conduction band (CB), leaving holes $\left(\mathrm{h}^{+}\right)$in the VB. MWNTs have a large electron-storage capacity (one electron for every 32 carbon atoms), and it is easy to capture photogenerated electrons $\left(\mathrm{e}^{-}\right)$from the $\mathrm{CB}$ of $\mathrm{ZnO}$, hindering the recombination of electronhole pairs. The photogenerated holes $\left(\mathrm{h}^{+}\right)$can migrate to the $\mathrm{ZnO}$ surface easily, and directly oxidize the adsorbed $\mathrm{MO}$ into $\mathrm{CO}_{2}$ and $\mathrm{H}_{2} \mathrm{O}$. Simultaneously, more photogenerated holes can react with adsorbed water to form hydroxyl radical $(\cdot \mathrm{OH})$, which is available to promote the decomposition of MO. Furthermore, the oxygen adsorbed on the surface of $\mathrm{ZnO}$ may accept $\mathrm{e}^{-}$and form $\cdot \mathrm{O}_{2}^{-}$, which also leads to the formation of $\cdot \mathrm{OH}$, resulting in degrading the MO. The process of electron transport in MWNTs/ZnO hybrids and photocatalytic degradation are shown in Fig. 11.

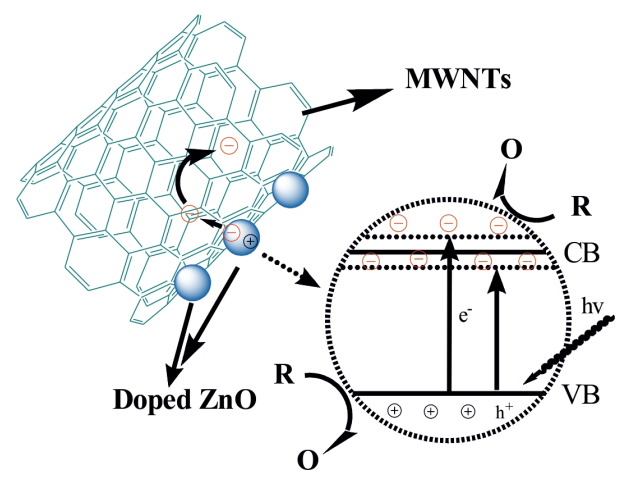

Fig. 11. The complete scheme of electron transfer in $\mathrm{MWNTs} / \mathrm{ZnO}$ hybrids and photocatalytic degradation.

\section{Conclusion}

In summary, $\mathrm{Mg}$-doped $\mathrm{ZnO}$ nanoparticles were successfully decorated onto the surface of MWNTs through the co-precipitation method. It is worth to note that the resultant MWNTs $/ \mathrm{Zn}_{0.9} \mathrm{Mg}_{0.1} \mathrm{O}$ hybrids have very strong 
green emission, and are proved to be highly active for photocatalytic degradation of methyl orange (MO). This is because MWNTs can act as photosensitizers for $\mathrm{ZnO}$ nanoparticles and hinder the recombination of electron-hole pairs. Moreover, incorporating $\mathrm{Mg}$ into $\mathrm{ZnO}$ can create an intermediate energy gap between the valence and conduction band of $\mathrm{ZnO}$, and promote the absorption of photons, resulting in creating more electron-hole pairs. Accordingly, the synthetic products have a potential application in fields of photocatalysis, sewage treatment and environmental protection.

\section{Acknowledgements}

C.S. Chen thanks the National Science Foundation of China (Nos. 21276028, 51154001, 51302021 and 11004018), Hunan Provincial Natural Science Foundation of China (Nos.09JJ3095 and 14JJ2077), National (Ministry of Land and Resources) Public Welfare Scientific Research (No.201011031), the Construct Program of the Key Discipline in Hunan Province, and Aid Program for Science and Technology Innovative Research Team in Higher Educational Instituions of Hunan Province for financial supports.

\section{References}

[1] Huang M.H., Mao S., Feick H., Yan H., Wu Y., Kind H., WebBer E., Russo R., YANG P., Science, 292 (2001), 1897.

[2] Rensmo H., Keis K., Lindstrom H., Sodergren S., Solbrand A., Hagfeldt A., Lindquist S.E., Wang L.N., Muhammed M., J. Phys. Chem. B, 101 (1997), 2598.

[3] Al-Hili S.M., Al-Mofarji R.T., Willander M., Appl. Phys. Lett., 89 (2006), 173119.

[4] Shannon R.D., Acta Crystallogr. A, 32 (1976), 751.

[5] Li H., Zhang Y.Z., PAN X.J., Zhang H.L., WANG T., XIE E., J. Nanopart. Res., 11 (2009), 917.

[6] Sahal M., Mari B., Mollar M., Manjon F.J., Phys. Status Solidi C, 79 (2010), 2306.

[7] Wang Y.S., Thomas P.J., O’Brien P., J. Phys. Chem. B, 43 (2006), 21412.

[8] YadaV M.K., Ghosh M., Biswas R., RaYchaudHUri A.K., MoOkerjee A., Phys. Rev. B, 76 (2007), 195450.

[9] Fujihara S., Ogawa Y., Kasai A., Chem. Mater, 16 (2004), 2965.

[10] Etacheri V., Roshan R., Viswanathan K., ACS Appl. Mater. Inter., 4 (2012), 2717.

[11] Woan K., Pyrgiotakis G., Sigmund W., Adv. Mater, 21 (2009), 2233.

[12] Chen C.S., Xie X.D., CaO S.Y., LiU T.G., Chen X.H., LIU Q.C., MeI Y.P., ZhaO G.J., Funct. Mater. Lett., 6 (2013), 1350018.
[13] Zhang Z.H., Phys. Rev. B, 66 (2002), 085405.

[14] Kongkanand A., Domynguez R.M., Kamat P.V., Nano Lett., 7 (2007), 676.

[15] KongKanand A., Kamat P.V., ACS Nano, 1 (2007), 13.

[16] Leary R., Westwood A., Carbon, 49 (2011), 741.

[17] Jiang L.Q., Gao L., Mater. Chem. Phys., 91 (2005), 313.

[18] Zhu L.P., Liao G.H., HuAng W.Y., Ma L.L., YANG Y., YU Y., FU S.Y., Mater. Sci. Eng. B-Adv., 163 (2009), 194.

[19] Khataee A.R., Zarei M., Desalination, 278 (2011), 117.

[20] Chen C.S., LiU T.G., Lin L.W., Xie X.D., Chen X.H., LIU Q.C., LIANG B., YU W.W., QIU C.Y., J. Nanopart. Res., 15 (2013),1295.

[21] Saleh T.A., Gondal M.A., Drmosh Q.A., YAMANi Z.H., Al-Yamani A., Chem. Eng. J., 166 (2011), 407.

[22] Chen X.H., Chen C.S., Chen Q., Mater. Lett., 57 (2002), 734.

[23] Chen C.S., Xie X.D., LiU T.G., Lin L.W., KuANG J.C., XIE X.L., Lu L.J., CAO S.Y., J Nanopart. Res., 14 (2012), 817.

[24] KiM T.H., PARK J.J., NAM S.H., PARK H.S., Cheong N.R., Song J.K., PARK S.M., Appl. Surf. Sci., 255 (2009), 5264.

[25] Lu X.Y., LiU Z.Y., Zhu Y., Jiang L., Mater. Res. Bull., 46 (2011), 1638.

[26] Aksoy S., Caglar Y., Ilican S., Caglar M., J. Alloy. Compd., 512 (2012), 171.

[27] Petrella A., Petrella M., Boghetich G., Mastrorilli P., Petruzzelli V., Ranieri E., Petruzzelli D., Ind. Eng. Chem. Res., 52 (2013), 2201.

[28] Bachilo S.M., Strano M.S., Kittrell C., Science, 298 (2002), 2361.

[29] Vanheusden K., Warren W.L., Seager C.H., Tallant D.R., Voigt J.A., J. Appl. Phys., 79 (1996), 7983.

[30] Das S., Chakrabarti S., Chaudhuri S., J. Phys. D Appl. Phys, 38 (2005), 4021.

[31] Kim D.T., YU K.S., KIM W.T., Kim C.D., PARK H.L., J. Mater. Sci. Lett., 11 (1992), 886.

[32] FAng D.Y., Li C.L., WAng N., Li P., Yao P., Cryst. Res. Technol., 48 (2013), 265.

[33] Yang X.L., Xu G.F., Li H.P., Zhu J.G., Wang X., Cryst. Res. Technol., 31 (1996), 521.

[34] Fujihara S., Ogawa Y., Kasai A., Chem. Mater., 16 (2004), 2965.

[35] Suwanboon S., Amornpitoksuk P., Proc. Eng., 32 (2012), 821. 